Document downloaded from:

http://hdl.handle.net/10251/103150

This paper must be cited as:

Genoves Gómez, V.; Vargas, F.; Gosálbez Castillo, J.; Carrión García, A.; Borrachero Rosado, MV.; Paya Bernabeu, JJ. (2017). Ultrasonic and impact spectroscopy monitoring on internal sulphate attack of cement-based materials. Materials \& Design. 125:46-54. doi:10.1016/j.matdes.2017.03.068

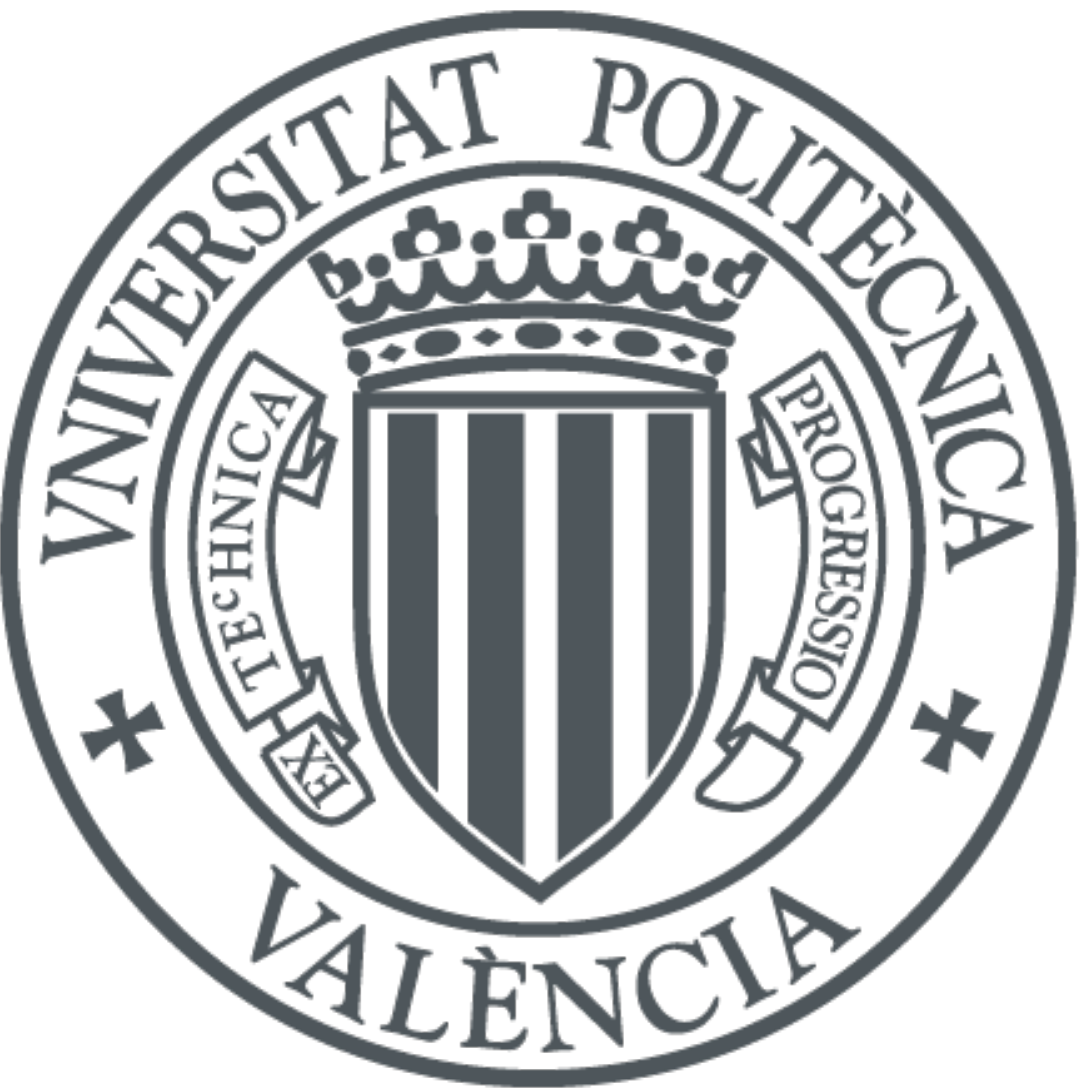

The final publication is available at

http://doi.org/10.1016/j.matdes.2017.03.068

Copyright Elsevier

Additional Information 


\title{
Ultrasonic and impact spectroscopy monitoring on internal sulphate attack of cement-based materials
}

\author{
V. Genovés ${ }^{\mathrm{a}, *}$, F. Vargas ${ }^{\mathrm{a}}$, J. Gosálbez ${ }^{\mathrm{b}, * *}$, A. Carrión ${ }^{\mathrm{b}}$, M. V. Borrachero ${ }^{\mathrm{b}}$, J. Payáa \\ ${ }^{a}$ ICITECH, Universitat Politècnica de València, Camino de Vera, $s / n 46022$ Valencia, Spain \\ ${ }^{b}$ ITEAM, Universitat Politècnica de València, Camino de Vera, s/n 46022 Valencia, Spain
}

\section{Abstract}

An exhaustive monitoring of an internal sulphate attack of Portland cement-based materials is addressed. Four series of Portland cement mortars with different amounts of gypsum $\left(0 \%-2 \% \mathrm{SO}_{3}\right.$ respect to the cement by mass) were monitored by means of physical, microstructural and non-destructive tests, studying specimens with a low expansion rate to examine the sensitivity of the applied techniques. The expansion analysis has shown the suitability of a fitting model, allowing the examination of two characteristic parameters: the characteristic time of the expansion reaction and the maximum amplitude of the expansion. In the mechanical analysis, higher values of $\mathrm{Rc}$ and $\mathrm{Rf}$ were attained as the gypsum content decreased. A microstructural analysis (thermogravimetry and FESEM) supported ettringite formation and expansion process. These results have been correlated with non-destructive tests: impact resonance acoustic spectroscopy and ultrasonic measures. The dynamic modulus and ultrasonic pulse velocity have closely predicted the stiffness of the specimens. The total material attenuation (absorbed energy of the chirp signal ultrasonic wave) presented different trends, showing clear differences for the most damaged series $\left(2 \% \mathrm{SO}_{3}\right)$. Attenuation supplied interesting information about the hardening process and the microcracking effect due to a mortar expansion higher than $0.04 \%$. The novelties of this study are the exhaustive monitoring of an internal sulfate attack, as well as the examination of the sensitivity of brand new NDT techniques when this damage process overlaps with the curing process.

Keywords:

Sulphate attack, Non-Destructive test, Chirp signal, Ultrasonics, Acoustic spectroscopy, Microstructure

\section{Introduction}

Sulphate attack is considered one of the most aggresive causes of concrete degradation. Ettringite triggers expansion mechanisms that have harmful effects on the Portland cement matrix, causing micro-cracking and, consequently, a reduction in the stiffness and strength. Primary ettringite has no negative effect because the expansions produced by the reaction between $\mathrm{C}_{3} \mathrm{~A}$ and the sulphate anions are absorbed by fresh concrete.

\footnotetext{
*Corresponding author E-mail address: vigegme@upv.com

** Corresponding author E-mail address: jorgocas@dcom.upv.es
} 
Secondary ettringite is formed for months, or even years after the concrete has been hardened [1]. The stresses that appear when an external or internal source of sulphate salts reacts with calcium aluminates hydrates (C-A-H) can spoil the matrix, causing micro-cracks, expansion and spalling. Additionally, gypsum is also formed by the reaction of sulphate ions and portlandite $[2,3]$. Moreover, delayed ettringite formation (DEF) happens when concrete products are cured at high temperatures, and the transformation of the monosulphoaluminate (Afm) phase to the trisulphoaluminate (Aft) phase also produces internal stress after thermal curing. There are two types of sulphate attack in concrete. The main difference between them is the location of the sulphate source: an external sulphate attack (ESA) and an internal sulphate attack (ISA). In an ESA process, sulphates present in the ground, water or air (like gypsum soils, rich sulphate-mineral waters, or $\mathrm{SO}_{3}$ polluted air) penetrate into the capillary network of the concrete and react with the C-A-H compounds, forming ettringite [4]. The stresses produce a damage gradient from the surfaces to the core of the element. In contrast, ISA 40 yields damage in the Portland cement matrix through the sulphates contained in the original mix (a high $\mathrm{SO}_{3}$ percentage in the cement used, aggregates with sulphate or sulphide minerals, mixing water with high sulphate concentration), releasing them over time. If the sulphates contained in the mix are free initially, the setting process of the concrete could be delayed, and also promote a loss of the early-age strength gain over time. In the ISA case, the damage homogeneously spreads throughout the concrete matrix. Also an homogeneous deterioration

45 process can be achieved when sulfide containing aggregates are oxidized by molecular oxygen in the air, and the sulfide is transformed to sulphate, which reacts towards C-A-H [5].

These degradation processes have become a worldwide problem responsible for the premature deterioration and development of pathologies in countless structures. It can be observed in certain circumstances if specific parameters are met simultaneously, including the concrete formula, the temperature at which the concrete has been exposed, and the presence of water. The conditions under which the degradation takes place, the impact of secondary ettringite formation on the properties of the concrete, and the techniques of diagnosis, are still subjects of intense debate [6]. Several authors have worked hard on understanding the large number of factors that play a role in ISA: sulfates and aluminates in the cement [6], drying and wetting cycles [7], temperature, etc. Some other studies have investigated the role of different additives and mineral additions to improve the behaviour of cement-

${ }_{55}$ based composites under sulphate attack [8-11]. All the aforementioned studies quantitatively characterize the mechanical damage to the concrete due to sulfate attack using different physical/mechanical parameters, such as the flexural strength, compressive strength, and long term linear strains (expansion). The microstructure of cement mortars are usually characterized by scanning electron microscope (SEM) equipped with energy dispersive X-ray spectroscopy (EDS). Moreover, recent studies have monitored the sulphate attack process with XRD [12] and combined methods with micro-tomography, obtaining significant additional information [13].

During recent years, non-destructive testing techniques (NDT) applied to concrete have been investigated, especially ultrasonics and impact resonance acoustic spectroscopy, in order to obtain new measures of the physical and mechanical properties of the materials without damaging the specimen under testing [14]. Studies using 
acoustic spectroscopy have shown remarkable results monitoring sulphate attack in cementitious composites by

65 means of linear and non-linear parameter determination [15, 16]. In ultrasonic-based NDT, one of the most widely used parameters, due to its robustness, is the ultrasonic pulse velocity (UPV). Some experimental studies have demonstrated that the UPV of P-waves is suitable for estimating the changes in the dynamic modulus of concrete depending on the sulphate attack damage $[8,9]$. Other studies based on ultrasound propagation have indicated that ultrasonic wave attenuation can be used to define different cementitious materials, distinguishing the microstructure, permeability or porosity, and other characteristics in both hardened [17-20] and fresh states [21].

The main aim of the present paper is to develop an exhaustive temporal monitoring of the evolution of mortars which have suffered an ISA with different degrees of damage by measuring different parameters, as well as correlating the results obtained using traditional techniques with other more new techniques based on NDT. The novelty of this study is not only the exhaustive monitoring of a damage process on a Portland cement composite with NDT techniques, but also the examination of the sensitivity of brand new NDT techniques when the damage process overlaps with the curing process (and the consequent stiffness and strength developments). This paper is structured as follows. Section 2 presents the materials studied as well as the different tests and measures used in this study to monitor the ISA process. Section 3 describes the results obtained from the application of the different tests to the specimens. Lastly, the conclusions are summarized in Section 4.

\section{Experimental}

Several tests and measures were carried out in this study in order to monitor the ISA process in Portland cement based systems (mortar and pastes). The tests were divided into three categories: physical, microstructural, and non-destructive tests. The expansion (Exp), compressive strength $\left(\mathrm{R}_{c}\right)$, and flexural strength $\left(\mathrm{R}_{f}\right)$ were determined by means of physical tests. For the microstructural tests, a high resolution thermogravimetry (HRTG) and field emission scanning electron microscopy (FESEM) were performed. Lastly, in the category of non-destructive tests (NDT), the dynamic modulus $\left(\mathrm{E}_{d y n}\right)$, ultrasonic pulse velocity $\left(\mathrm{v}_{p}\right)$, and ultrasonic wave attenuation $\left(\alpha_{\text {mat }}\right)$ were determined. All tests performed for each series are summarized in Table 1.

Table 1: Chronogram of the tests performed for all mortar/paste series at different ages (days).

\begin{tabular}{|c|c|c|c|c|c|c|c|c|c|c|c|c|c|c|c|c|c|c|c|c|c|}
\hline Tests & Days & 3 & 7 & 10 & 14 & 17 & 21 & 24 & 28 & 35 & 42 & 50 & 56 & 64 & 70 & 77 & 84 & 90 & 120 & 150 & 180 \\
\hline \multirow[t]{3}{*}{ Physical } & Exp & $\bullet$ & $\bullet$ & $\bullet$ & $\bullet$ & $\bullet$ & $\bullet$ & $\bullet$ & $\bullet$ & $\bullet$ & $\bullet$ & $\bullet$ & $\bullet$ & $\bullet$ & $\bullet$ & $\bullet$ & $\bullet$ & $\bullet$ & $\bullet$ & $\bullet$ & $\bullet$ \\
\hline & $\mathrm{R}_{c}$ & & $\bullet$ & & $\bullet$ & & & & $\bullet$ & & & & $\bullet$ & & & & & $\bullet$ & & & $\bullet$ \\
\hline & $\mathrm{R}_{f}$ & & $\bullet$ & & $\bullet$ & & & & $\bullet$ & & & & $\bullet$ & & & & & $\bullet$ & & & $\bullet$ \\
\hline \multirow[t]{2}{*}{ Microstructural } & HRTG & & & & & & & & & & & & & & & & & $\bullet$ & & & $\bullet$ \\
\hline & FESEM & & & & & & & & & & & & & & & & & $\bullet$ & & & \\
\hline \multirow[t]{3}{*}{ NDT } & $\mathrm{E}_{d y n}$ & $\bullet$ & $\bullet$ & $\bullet$ & $\bullet$ & $\bullet$ & $\bullet$ & $\bullet$ & $\bullet$ & $\bullet$ & $\bullet$ & $\bullet$ & $\bullet$ & $\bullet$ & $\bullet$ & $\bullet$ & $\bullet$ & $\bullet$ & $\bullet$ & $\bullet$ & $\bullet$ \\
\hline & $\mathrm{v}_{p}$ & $\bullet$ & $\bullet$ & $\bullet$ & $\bullet$ & $\bullet$ & $\bullet$ & $\bullet$ & $\bullet$ & $\bullet$ & $\bullet$ & $\bullet$ & $\bullet$ & $\bullet$ & $\bullet$ & $\bullet$ & $\bullet$ & $\bullet$ & $\bullet$ & $\bullet$ & $\bullet$ \\
\hline & $\alpha_{\text {mat }}$ & $\bullet$ & $\bullet$ & $\bullet$ & $\bullet$ & $\bullet$ & $\bullet$ & $\bullet$ & $\bullet$ & $\bullet$ & $\bullet$ & $\bullet$ & $\bullet$ & $\bullet$ & $\bullet$ & $\bullet$ & $\bullet$ & $\bullet$ & $\bullet$ & $\bullet$ & • \\
\hline
\end{tabular}




\subsection{Materials and specimens}

90 A 40x40x160 $\mathrm{mm}^{3}$ geometry was chosen for the mortar specimens, using various dosages to obtain four series with different rates of ISA damage varying the total $\mathrm{SO}_{3}$ content. In Table 2, the dosages for the four performed series are summarized. Twenty-four mortar mixes were prepared according to the Spanish standard UNE-EN 196 to obtain three specimens per batch, which were used for physical and non-destructive tests. Additionally, four pastes were made to perform micro-structural tests following the proportions in Table 2. After the iron moulds

95 were filled with the fresh mortar, they were stored in a wet chamber $\left(20^{\circ} \mathrm{C}\right.$ and $\left.100 \% \mathrm{RH}\right)$ for 24 hours. After that, the specimens were removed from the moulds and cured under water at $20^{\circ} \mathrm{C}$ for the whole duration of the experiment.

The cement used in this experiment was a Spanish CEM BL II/A-L 42,5-R with 5.95\% tricalcium aluminate $\left(\mathrm{C}_{3} \mathrm{~A}\right)$ and $4.63 \% \mathrm{SO}_{3}$ by weight. The rest of main components were $19.27 \% \mathrm{SiO}_{2}, 2.45 \% \mathrm{Al}_{2} \mathrm{O}_{3}, 65.85 \% \mathrm{CaO}, 0.1 \%$ $\mathrm{Na}_{2} \mathrm{O}, 0.74 \% \mathrm{~K}_{2} \mathrm{O}, 0.4 \% \mathrm{MgO}, 6.48 \%$ LOI by weight.

The sulphate source was pure $\mathrm{CaSO}_{4} \cdot 2 \mathrm{H}_{2} \mathrm{O}$ (gypsum) and the aggregate was a normalized silica sand (NORMSAND). The ratio of water to binder (cement+gypsum) was maintained constant for all dosages in this experiment (0.5). Four mortar series were prepared, in which the added gypsum produced an increasing $\mathrm{SO}_{3}$ content: in $0 \%$, $1 \%, 1.5 \%$, and $2 \%$.

Table 2: Dosages for mortar mix series by weight $[\mathrm{g}]$.

\begin{tabular}{llllll}
\hline Series & Sand & Cement & Water & Gypsum & added $\mathrm{SO}_{3}[\%]$ \\
\hline $0 \%$ & 1350.0 & 450.0 & 225.0 & 0 & 0 \\
$1 \%$ & 1350.0 & 440.3 & 225.0 & 9.7 & 1 \\
$1.5 \%$ & 1350.0 & 435.5 & 225.0 & 14.5 & 1.5 \\
$2 \%$ & 1350.0 & 430.6 & 225.0 & 19.4 & 2 \\
\hline
\end{tabular}

\subsection{Physical tests}

Physical tests were performed in order to monitor the ISA process and correlate the destructive and conventional parameters with the non-destructive ones. As mentioned earlier, 24 mixes (6 for each dosage) were prepared for the physical and NDT, 4 of them (one per dosage) for expansion and NDT (and also for the last destructive test), and the remaining 20 (5 per dosage) for the intermediate destructive tests (determining flexural and compressive strength) at different ages.

In order to monitor the expansion undergone by the specimens, the Demec extensometry (mechanical strain gauge) method was used instead of that proposed by the ASTM standard [22]. The equipment was a Mituyoto ID-C112MB $( \pm 1 \mu \mathrm{m})$ extensometer, and metal disks were attached centred on the two adjacent faces (excluding the rough face) with $10 \mathrm{~cm}$ separation between them. Thus, 6 measurements (2 measurements for each specimen, 3 specimens per series) per series and expansion test age were carried out. 
For the mechanical tests (determining the compressive and flexural strengths) an universal testing machine was used (INSTRON model 3382) following the Spanish standard UNE-EN-196. For each curing age and series, three specimens were tested by means of three-point bending tests $\left(\mathrm{R}_{f}\right)$ and the six obtained semi-prisms were used to determine the compressive strength $\left(\mathrm{R}_{c}\right)$.

\subsection{Microstructural tests}

For the purpose of determining the internal changes of the hydrated Portland cement matrix, a microstructural analysis was carried out by means of HRTG and FESEM. These analyses were carried out on the pastes, which had the same dosage as the mortars, excluding the sand.

The HRTG tests were performed in order to support the formation of ettringite formed for all pastes. In order to carry out this analysis, portions of the paste samples were taken and pulverized with an agate mortar, adding a small amount of acetone. The solid was filtered and dried at $60^{\circ} \mathrm{C}$ for $15 \mathrm{~min}$. The equipment used was an ultrabalance Mettler TGA 850. Sealed aluminium crucibles of $100 \mathrm{ml}$ were used, each with a lid with a micro-hole to create a water vapour self-generated atmosphere [23]. The analysis was carried out in a dry nitrogen atmosphere with a gas flow of $75 \mathrm{~mL} / \mathrm{min}$ and a temperature interval of $35^{\circ} \mathrm{C}-300^{\circ} \mathrm{C}$. For high resolution thermogravimetric analysis (Max-Res, Stare software), the lowest heating rate was $0.1^{\circ} \mathrm{C} / \mathrm{min}$ and the highest one $10^{\circ} \mathrm{C} / \mathrm{min}$. The heating rate was changed according to the mass loss rate. The highest heating rate was achieved for mass loss rates lower than $1 \mu \mathrm{g} \mathrm{s}^{-1}$, and the lowest heating rate was achieved for mass loss rates higher than $3 \mu \mathrm{g} \mathrm{s}^{-1}$. This analysis was carried out to be more sensitive in detecting peaks on thermogravimetric derivative curves (DTG) when the various decomposition processes are very close in their temperature range (the case of decomposition of calcium silicate hydrates and ettringite). The main decomposition DTG peak related to the calcium silicate hydrates is recorded in $110^{\circ} \mathrm{C}-130^{\circ} \mathrm{C}$, that for the ettringite within the $140^{\circ} \mathrm{C}-150^{\circ} \mathrm{C}$ range, and those for the calcium aluminosilicate and calcium aluminate hydrates within the $210^{\circ} \mathrm{C}-220^{\circ} \mathrm{C}$ range [16]. For the FESEM observations, portions of the paste samples were taken, drying at $60^{\circ} \mathrm{C}$ and coating them with a carbon layer. A ZEISS (ULTRA 55) electron microscope was used, setting it to voltages of $2-3 \mathrm{kV}$ and to distances between $3.9 \mathrm{~mm}$ and $6.0 \mathrm{~mm}$.

\subsection{Non-Destructive tests}

\subsubsection{Impact resonance acoustic spectroscopy}

The dynamic modulus $\left(\mathrm{E}_{d y n}\right)$ is a mechanical parameter highly correlated with the Young modulus in concrete [14]. Some studies have demonstrated the quasi-equivalence between both parameters [15], with $\mathrm{E}_{d y n}$ being an accurate indication of the stiffness of the concrete, without the need for destroying the specimen during the test. To determine $\mathrm{E}_{d y n}$ (transverse mode), an ASTM standardized method was used [24]. Specimens were placed in an acoustic foam absorber surface and were struck ten times with a known mass sphere in the centre of the larger faces of the prismatic specimens. The signal was collected with a piezoelectric accelerometer sensor. The 
frequency was extracted from the frequency domain signal and mean values were calculated. After that, the corresponding ASTM equation was used to obtain $\mathrm{E}_{d y n}$. Details about the layout can be seen in Figure 1.

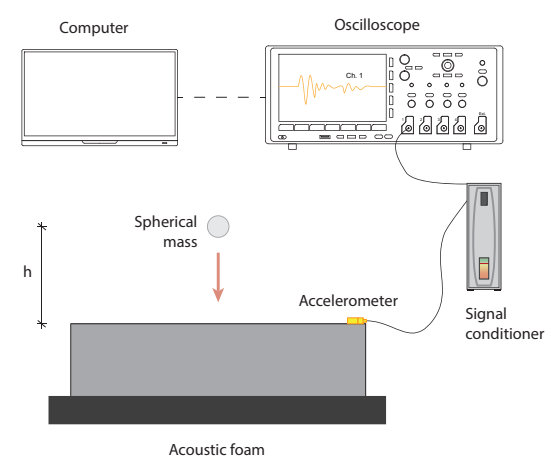

Figure 1: Scheme of equipment used in the resonant frequency test.

\subsubsection{Ultrasonic measurements}

Different layouts can be used to make an ultrasonic inspection. In this study, a through-transmission setup was selected, since it offers good penetration and good accuracy for estimating the velocity and attenuation[17, 25-27]. The transducers (transmitter and receiver) used were the K1SC from General Electric. Both are broadband transducers with a bandwidth centred at $1 \mathrm{MHz}$. The transmitter transducer was excited directly by a programmable signal generator (Agilent 33120A) and the reception transducer was connected to a $40 \mathrm{~dB}$ preamplifier (Panametrics 5600B). The received and amplified ultrasonic signal was captured by a digital oscilloscope (Tektronix DPO3014) with a sampling frequency of $12.5 \mathrm{MHz}$. Finally, a laptop was used to control the signal generator and to acquire and store the digitized signals. The ultrasonic transducers were placed facing the longitudinal axis of the prismatic specimen, and they were fixed by two plastic clamps: a movable one to adjust to the specimen, and a fixed one. Pure vaseline at the transducer-specimen interfaces was used as an impedance coupling medium. Further details about the layout can be seen in Figure 2.

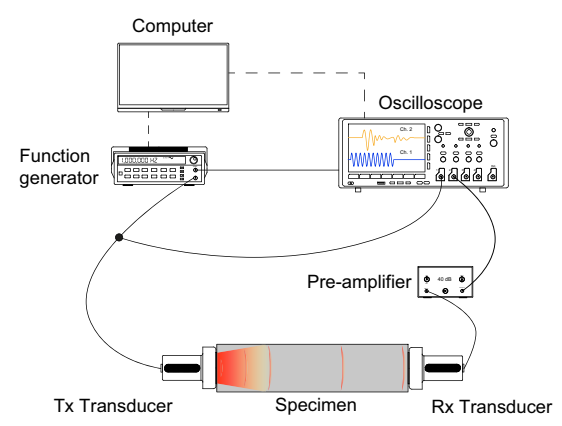

Figure 2: Scheme of equipment used in a typical ultrasonic inspection.

The transmitted signal $s_{t x}$ was a swept-frequency signal (chirp). The mathematical expression of a linear chirp 
signal is

$$
\begin{gathered}
s_{t x}(t)=A_{t x} \cos \left(2 \pi f_{0} t+\pi \Delta_{f_{\max }} t^{2}\right) \cdot \operatorname{rect}\left(\frac{t-\frac{T}{2}}{T}\right) \\
\Delta_{f_{\max }}=\frac{f_{\max }-f_{0}}{T}
\end{gathered}
$$

165

where $A_{t x}$ is the amplitude of the signal, $t$ is the time, $f_{0}$ is the fundamental frequency, $T$ is the active time of the signal, and $\Delta_{f_{\max }}$ controls the maximum frequency $\left(f_{\max }=f_{0}+T \Delta_{f_{\max }}\right)$ which is reached at $T$ seconds (Eq. 2). The selected parameters were $A_{t x}=10 \mathrm{~V}, f_{0}=100 \mathrm{kHz}, f_{\max }=1 \mathrm{MHz}$ and $T=200 \mu \mathrm{s}$.

The estimated ultrasound parameters from the received ultrasonic signal are the wave velocity and the total attenuation of the material. With $s_{r x}(t)$ the amplitude of the received signal, the propagation velocity (or UPV), $v_{p}$, is obtained as the ratio between the length of the specimen, $d_{\text {mat }}$, and the signal time arrival, $\tau_{a}$ (Eq. (3)). The signal time arrival, $\mathrm{t}_{a}$, was taken to be when $x_{r x}$ exceeded $50 \%$ of the noise level of the received signal.

$$
v_{p}[m / s]=\frac{d_{m a t}}{t_{a}}
$$

The ultrasonic wave attenuation due to the material, $\alpha_{m a t}$, can be calculated from the transmitted and received energies, taking into consideration the effect of the equipment and the distance travelled. Given the analytical expression and the specific parameters of the transmitted signal (Eq. 1), the transmitted energy $E_{t x}$ can be obtained theoretically using Eq. (4). In this paper, $E_{t x}$ equals $10 \mathrm{~mJ}$ and is constant throughout the test.

$$
E_{t x}[J]=\int_{0}^{\infty}\left|s_{t x}(t)\right|^{2} d t=\frac{A_{t x}^{2} T}{2}+\frac{A_{t x}^{2}}{2} \int_{0}^{T} \cos \left(2 \pi\left(2 f_{0}\right) t+\pi\left(2 \Delta f_{\max }\right) t^{2}\right) d t \approx \frac{A_{t x}^{2} T}{2}
$$

The total received energy, $E_{r x}(t)$, is the energy of the received signal acquired by the oscilloscope, obtained according to Eq. (5).

$$
E_{r x}[\mathrm{~J}]=\int_{0}^{\infty} s_{r x}^{2}(t) d t
$$

The global attenuation associated to the measurement equipment (transducers, amplifier, wires, acquisition module, ... ) , $\alpha_{\text {equip }}$, is independent of the tested material and is constant over the test. In this paper, $\alpha_{\text {equip }}=$ $180-5 \mathrm{~dB}$. The value of the preamplifier must also be subtracted $\left(\alpha_{\text {preamp }}=40 \mathrm{~dB}\right)$.

Considering all the aforementioned terms, the total attenuation of the material, $\alpha_{\text {mat }}$, is obtained according to Eq. (6).

$$
\alpha_{\text {mat }}[\mathrm{dB} / \mathrm{cm}]=\frac{10 \cdot \log \left(E_{t x}[\mathrm{~J}]\right)-10 \cdot \log \left(E_{r x}(t)[\mathrm{J}]\right)-\alpha_{\text {equip }}[\mathrm{dB}]-\alpha_{\text {preamp }}[\mathrm{dB}]}{d_{\text {mat }}[\mathrm{cm}]}
$$




\section{Results and discussion}

\subsection{Physical tests}

The prismatic mortars were stored under water after demoulding. In the samples with $\mathrm{SO}_{3}$ added (in the chemical form of gypsum), the reaction between the calcium aluminates and the sulfate anions becomes very rapid, because of the high solubility of gypsum (ca. $2 \mathrm{~g} / \mathrm{L}$ at $20^{\circ} \mathrm{C}$ ) in water. In these conditions, the formation of secondary ettringite is achieved according to the following chemical equation:

$$
3 \mathrm{CaO} \cdot \mathrm{Al}_{2} \mathrm{O}_{3}+3\left(\mathrm{CaSO}_{4} \cdot 2 \mathrm{H}_{2} \mathrm{O}\right)+26 \mathrm{H}_{2} \mathrm{O} \longrightarrow 3 \mathrm{CaSO}_{4} \cdot 3 \mathrm{CaO} \cdot \mathrm{Al}_{2} \mathrm{O}_{3} \cdot 32 \mathrm{H}_{2} \mathrm{O}
$$

The great molar volume of ettringite $\left(710.32 \mathrm{~cm}^{3} / \mathrm{mol}\right)$ promotes internal stress in the cementing matrix, and this yields an expansion. The expansion values $(\epsilon(t))$ of specimens with different amounts of added $\mathrm{SO}_{3}$ were measured at different ages, and the expansion curves are given in Figure 3a. The control series, 0\%, showed a small axial deformation due to the $\mathrm{SO}_{3}$ content in the cement and hydrothermal changes (the temperature and humidity during the testing process). The rest of the series experienced significant expansion values at short and long curing times. It is noticeable that the maximum expansion value, $0.072 \%$ (produced for the $2 \%$ sample after 180 days of curing), is lower than the maximum allowed value (0.1\%) established by the ASTM C 1157 for non-expansive cements after 15 weeks. Thus, the different characterization techniques need to have a high level of sensitivity in order to characterize well the different degrees of damage studied in this work.

On the basis of these results, we were able to evaluate the effect of the presence of additional gypsum in comparison with the control series ( $0 \%$ ). For this, two characteristic parameters ( $\epsilon^{\infty}$ and $\tau_{\text {char }}$ ) were determined to describe the expansion curves (solid line in Fig. 3a) and to predict future trends (dashed line in Fig. 3a) for each series, using the equation proposed by Larive [28] and given below.

$$
\epsilon(t)=\frac{\sigma}{K}+\epsilon^{\infty} \cdot\left(1-e^{-\frac{t}{\tau_{\text {char }}}}\right)
$$

Here, $\sigma$ is the external force applied to the concrete element, $K$ is the elastic modulus of the concrete, $\epsilon^{\infty}$ is the maximum amplitude of the expansion, and $\tau_{\text {char }}$ is the characteristic time of the expansion reaction (influencing the slope of the curve). In this case, $\sigma$ is 0 due to the non-existence of any force applied to the specimens, making null the first term of Eq. 8.

The fitted parameters according to Eq. 8 are summarized in Table 3. It is apparent that adding extra amounts of gypsum increases the characteristic time of the expansion reaction $\left(\tau_{c h a r}\right)$ as well as increasing the amplitude of the expansion $\left(\epsilon^{\infty}\right)$. From these results it is obvious that the percentages (of added $\mathrm{SO}_{3}$ ) were very low, suggesting that the formation of ettringite is reduced. The value of $\epsilon^{\infty}$ for the $1 \%$ series is only $0.025 \%$, whereas it increased three times $(0.072 \%)$ for the $2 \%$ series. This behaviour is due to the increase in the stress when the amount of ettringite formed surpasses the available pore volume for ettringite crystallization. Thus, a non-linear behaviour of the expansion with the added $\mathrm{SO}_{3}$ has been obtained. 


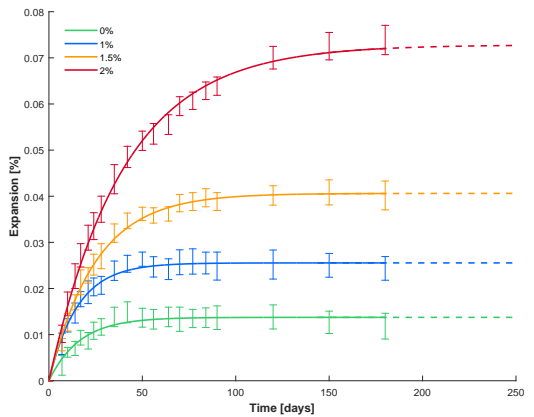

(a)

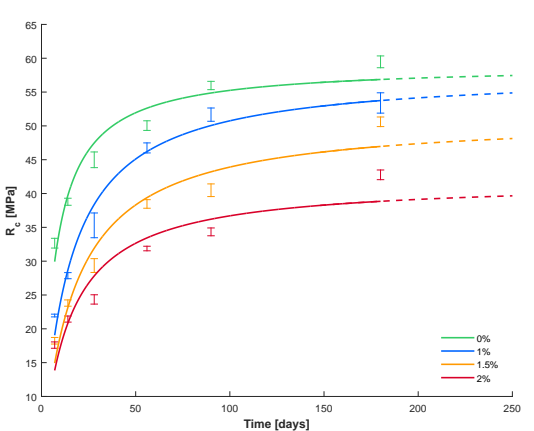

(b)

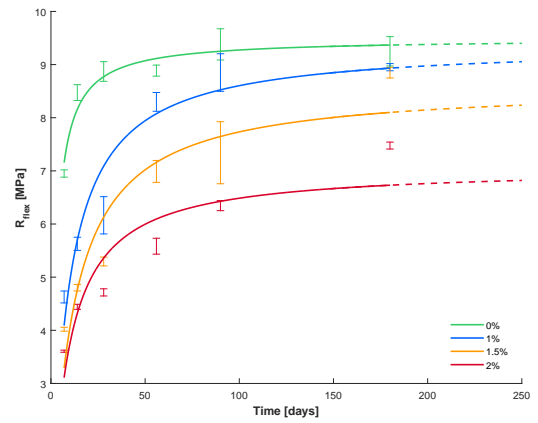

(c)

Figure 3: Results of physical tests for all series. Figure 3a shows the expansion undergone by the specimens. Each errorbar represents 6 measurements. Figure 3b shows the evolution over time of the compressive strength. Each errorbar represents 6 measurements. Figure 3c shows the evolution over time of the flexural strength. Each errorbar represents 3 measurements.

Figures $3 \mathrm{~b}$ and $3 \mathrm{c}$ show the evolution of the compressive and flexural strengths. As the percentage of gypsum increases, not only does the cement hydration process slow down, but also different maximum values of the mechanical strength are achieved. After 180 days, in the case of the compressive strength, the 1\%, 1.5\% and 2\% series reached values of $10 \%, 15 \%$, and $20 \%$ less than the $0 \%$ series, respectively. However, in the case of the flexural strengths, the $1 \%$ and $1.5 \%$ series reach strengths only $3 \%$ and $4 \%$ lower. This indicates that the presence of sulphates generated a delay in the evolution of the strength, but without provoking significant structural damage. However, in the case of the $2 \%$ series, the compressive strength is $28 \%$ lower and the flexural strength is $20 \%$ lower than for the $0 \%$ series. In the ISA, the available sulphate is limited to that present in the cement and the added one. Consequently, as the reaction progress, the sulphate is consumed, and the concentration of sulphate into the pore solution decreases. This delays the evolution of the strength and conditions its maximum value but a great expansion is not achieved because sulphate is consumed, no further strength decrease is produced along the time. On the contrary, for ESA the available sulphate is not limited and consequently a continuous decrease in mechanical properties is observed during the attacking process [29].

Apart from the experimental results, the fitted models according to ACI [30] are represented. This standard establishes the curves of the evolution of the compressive strength versus the curing time for non-damaged series (Eq. 9).

$$
R_{c}(t)=\frac{t}{\gamma+t} \cdot R_{c}^{\infty}
$$

Here, $\mathrm{R}_{c}^{\infty}$ is the ultimate compressive strength and $\gamma$ is the age of concrete at which one-half of the ultimate compressive strength of concrete is reached. In this paper, we have employed the expression for both the compressive and flexural strength in order to model the curves. Note that the fit (measured by means of $R^{2}$ value) decreases in the case of the flexural strengths and for highest values of $\mathrm{SO}_{3}$ (Table 3). Adding extra gypsum produces less compressive/flexural strength and an older age to reach that ultimate strength. 
Table 3: Fitting parameters for expansion (according to Eq. 8) and for compressive and flexural strengths (according to Eq. 9) of mortars of the $0 \%$ (control), $1 \%, 1.5 \%$ and $2 \% \mathrm{SO}_{3}$ series.

\begin{tabular}{|c|c|c|c|c|c|c|c|c|c|}
\hline \multirow[b]{2}{*}{ Series } & \multicolumn{3}{|c|}{ Expansion } & \multicolumn{3}{|c|}{ Compressive strength } & \multicolumn{3}{|c|}{ Flexural strength } \\
\hline & $\epsilon^{\infty}[\%]$ & $\tau_{\text {char }}$ [days] & $R^{2}$ & $\mathrm{R}_{c}^{\infty}[\mathrm{MPa}]$ & $\gamma_{c}$ [days] & $R^{2}$ & $\mathrm{R}_{f}^{\infty}[\mathrm{MPa}]$ & $\gamma_{f}$ [days] & $R^{2}$ \\
\hline $0 \%$ & 0.013 & 16.00 & 0.939 & 59.00 & 6.79 & 0.944 & 9.48 & 2.27 & 0.940 \\
\hline $1 \%$ & 0.025 & 15.29 & 0.984 & 58.01 & 14.31 & 0.974 & 9.38 & 9.061 & 0.923 \\
\hline $1.5 \%$ & 0.040 & 24.76 & 0.994 & 51.42 & 17.11 & 0.944 & 8.60 & 11.32 & 0.883 \\
\hline $2 \%$ & 0.072 & 39.87 & 0.998 & 41.90 & 14.17 & 0.890 & 7.06 & 8.89 & 0.847 \\
\hline
\end{tabular}

\subsection{Microstructural tests}

In order to estimate the ettringite formed in mortar specimens, an HRTG analysis and FESEM observations were performed. Thermogravimetric analysis is an instrumental technique that allows us to correlate mass change and temperature. In particular, due to the mass losses related to the thermal decompositions of the C-S-H $\left(110^{\circ} \mathrm{C}-130^{\circ} \mathrm{C}\right)$ and ettringite $\left(130^{\circ} \mathrm{C}-150^{\circ} \mathrm{C}\right)$ would overlap in the temperature domain using the traditional thermogravimetry test: in this research, a high-resolution thermogravimetric analysis was done. HRTG is based on a dynamic process which progressively changes the heating rate depending on the mass loss rate, allowing to separate the thermal decomposition events corresponding to the hydrated products from the Portland cement. It allows properly quantifying the mass loss related to the content of C-S-H and ettringite, as was done in previous studies $[16,31]$. The results of the mass loss for the C-S-H and ettringite at 90 and 180 curing days for each series are set out in Table 4. In general, there can be seen an increase in the ettringite and a decrease in the mass loss associated to the C-S-H content with time (90 to 180 days) for all series: the more $\mathrm{SO}_{3}$ content is added, the more the ettringite formation increases with time. The decrease in the C-S-H with the $\mathrm{SO}_{3}$ supports the mechanical results: as the $\mathrm{C}-\mathrm{S}-\mathrm{H}$ content increases, better mechanical behaviour ensues. In the case of the $2 \%$ series, the C-S-H formation at 180 days breaks up the general trend of all series: it did not decrease as the $\mathrm{SO}_{3}$ content rose, maybe caused by the fact that the rate of the chemical reactions of the matrix through time are different when the gypsum content in the initial mix is relatively high.

The FESEM observations were taken after 90 days of curing for all series. Representative micrographs are shown in Figure 4. Figure 4a shows the C-S-H and portlandite phases, without noticeable ettringite crystals in the $0 \%$

Table 4: Mass loss (in percent) related to C-S-H and ettrigite decomposition peaks in the HRTG analysis for each series.

\begin{tabular}{|c|c|c|c|c|}
\hline \multirow[b]{2}{*}{ Series } & \multicolumn{2}{|l|}{ C-S-H } & \multicolumn{2}{|c|}{ Ettringite } \\
\hline & 90 days & 180 days & 90 days & 180 days \\
\hline $0 \%$ & 4.68 & 4.60 & 3.22 & 3.41 \\
\hline $1 \%$ & 4.42 & 4.10 & 3.79 & 4.08 \\
\hline $1.5 \%$ & 4.41 & 4.07 & 3.81 & 4.17 \\
\hline $2 \%$ & 4.25 & 4.24 & 4.00 & 4.45 \\
\hline
\end{tabular}


series. In Figures 4b and 4c (1\% and 1.5\% series, respectively), needles of ettringite are identified together with portlandite crystals and C-S-H gel. Lastly, a micrograph of the $2 \%$ series is shown in Figure $4 d$. In this image, a large amount of ettringite needles surrounding the C-S-H gel and portlandite can be seen. The observations from these micrographs support the ettringite content found in the HRTG.

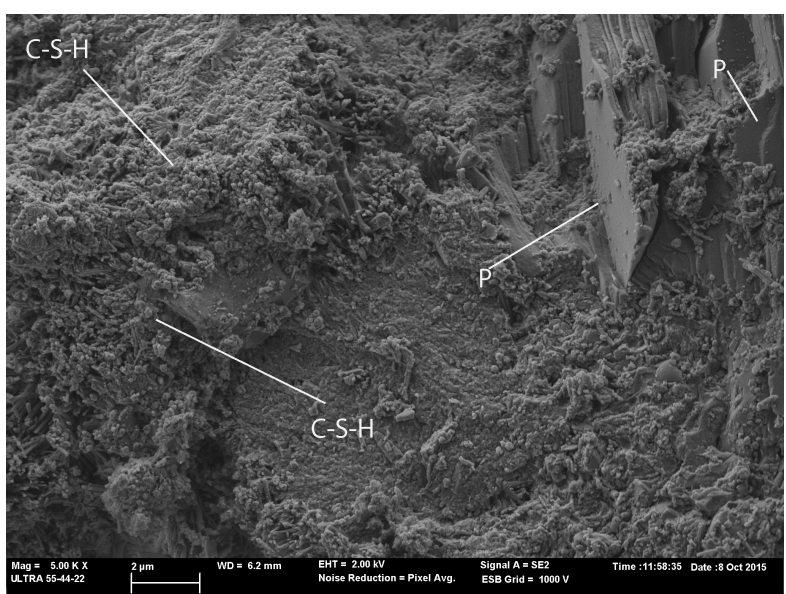

(a) $0 \%$ series

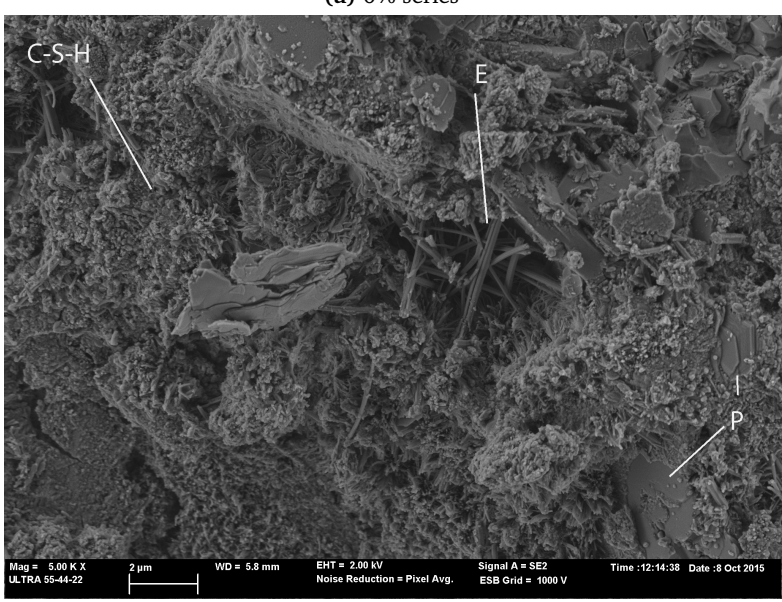

(c) $1.5 \%$ series

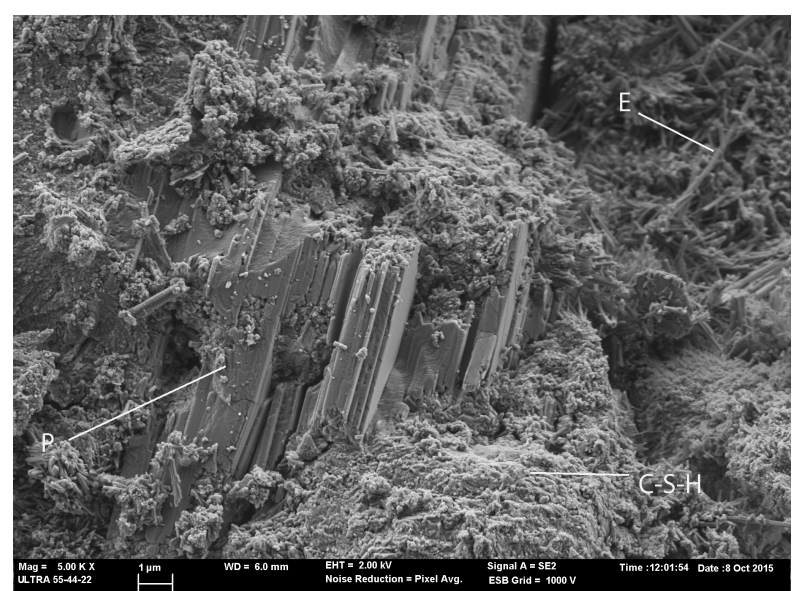

(b) $1 \%$ series

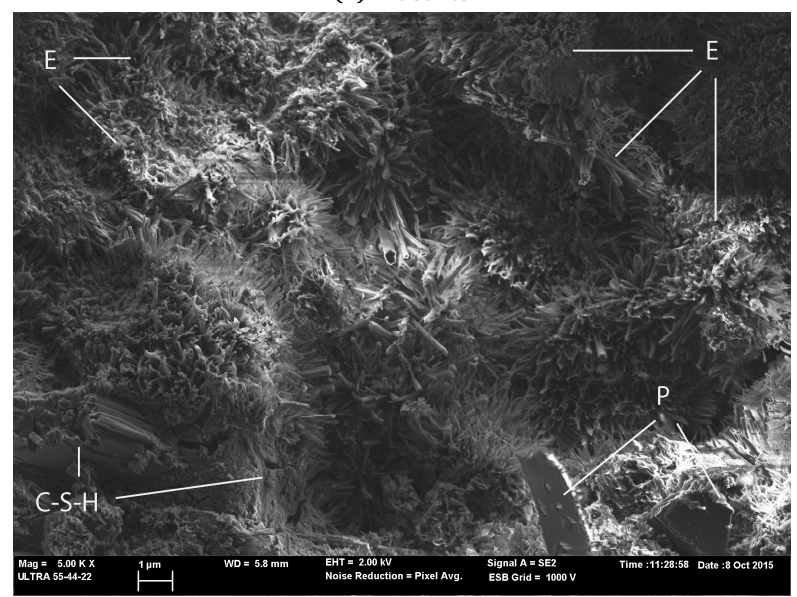

(d) $2 \%$ series

Figure 4: FESEM images for the ISA series taken after 90 days of curing: $4 \mathrm{a} 0 \%$ series, $4 \mathrm{~b} 1 \%$ series, $4 \mathrm{c} 1.5 \%$ series, $4 \mathrm{~d} 2 \% \mathrm{SO}_{3}$ series. Note that all of them were taken with the same magnification (5000x). (key: C-S-H: calcium silicate hydrate, E: ettringite, P: portlandite) 


\subsection{Non-Destructive tests}

\subsubsection{Impact resonance acoustic spectroscopy}

The dynamic modulus $\left(\mathrm{E}_{d y n}\right)$ was calculated from the fundamental transverse frequency obtained from the impact resonance acoustic test (ASTM C215 - 14 [24]). This parameter was monitored in order to follow the evolution of the stiffness for all series (Fig. 5a). The $0 \%$ series presented a normal stiffness evolution due to the lack of additional gypsum in the initial mix. This allows the matrix to evolve quickly, as the mechanical results suggested in the previous section, Section 3.1. The $1 \%$ and 1.5\% series experience a slowdown process in the evolution of the $\mathrm{E}_{d y n}$ parameter due to the delay effect in the hydration process of the cement matrix caused by the addition of gypsum. However, the values of $\mathrm{E}_{d y n}$ for these two series converged after 180 days to the value obtained for the $0 \%$ series. This behaviour means that an expansion under $0.04 \%$ has no significant effect on $\mathrm{E}_{d y n}$. Interestingly, the $2 \%$ series showed a similar trend, with $\mathrm{E}_{d y n}$ increasing with the curing time. However, in contrast to the findings for the other series, the maximum value of $\mathrm{E}_{d y n}$ was significantly lower. Figure $5 \mathrm{~b}$ shows the relation between the normalized dynamic modulus and the expansion experienced by the specimens. The derivative of each expansion curve has been calculated, in order to remove points with no increase in the expansion from the linear fit plot (the expansion process stopped; removed experimental points are marked as filled symbols). In this graph, the change in the slope of the different series can be clearly observed, showing a clear relation between the gain in stiffness of the series as the ISA progresses.

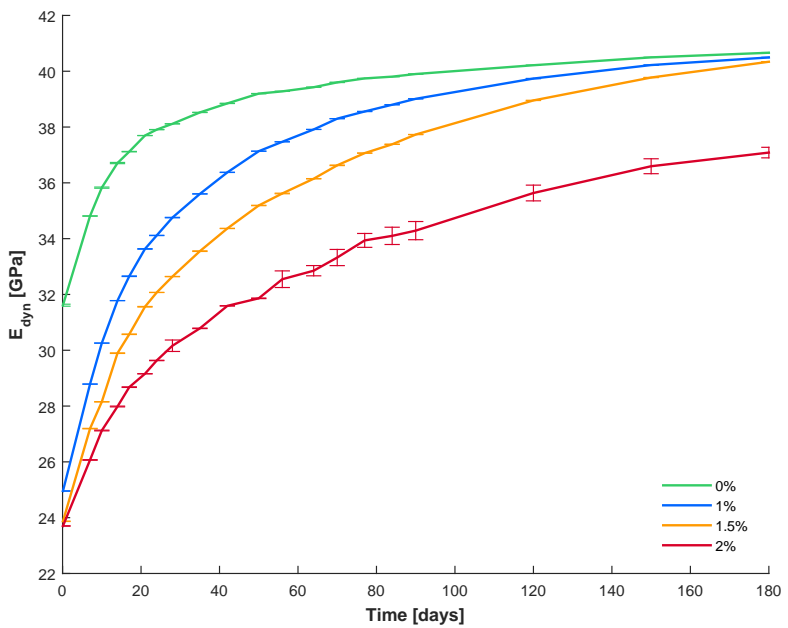

(a)

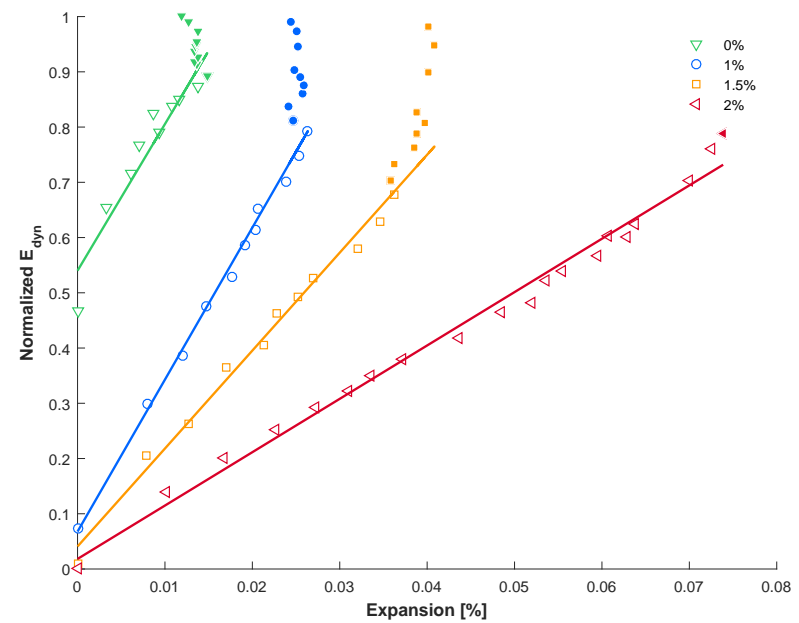

(b)

Figure 5: Results of impact resonance acoustic spectroscopy tests for all series. Figure 5a: the evolution of the dynamic modulus. Each errorbar represents 30 measurements. Figure 5b: the relation between the normalized dynamic modulus (calculated by means of the ratio between the dynamic modulus for a given test time and the dynamic modulus value reached after 180 days) and the expansion experienced by the specimens. The derivative of each expansion curve has been calculated in order to remove from the linear fit plot those experimental points for which there was no increase in the expansion (filled scatters).

In the case of the $0 \%$ and $1 \%$ series, the slope of the linear fit is equal, but the regression for the $0 \%$ series starts at higher values due to the quick gain in stiffness. However, the $1.5 \%$ and $2 \%$ series decrease their slopes, indicating a loss of speed in the curing process. A normalization with respect to the maxima of all values of $\mathrm{E}_{d y n}$ 
was necessary in order to make an accurate analysis of the geometry of the fitting for all series.

This behaviour demonstrates that there is no relation between the evolution of the dynamic modulus and the expansion of the material due to the internal sulphate attack. Probably a low level of a microcracking process is not easily identified by means of the impact resonant acoustic technique, due to the non-activation of micro-cracking process typical of high stage damaging process in ISA. Nonetheless, the $2 \%$ series did not reach the same values of $\mathrm{E}_{d y n}$, due to the large amount of gypsum added in the initial mix and, consequently, the large amount of ettringite formed in the hydrated cement matrix. For high levels of damage, the impact resonant acoustic technique is suitable.

\subsubsection{Ultrasonic measurements}

The computation of the ultrasonic velocity $v_{p}$, proportional to the mechanical constants of the material, basically consists in the estimation of the time arrival $t_{a}$. Figure 6a shows the initial part of the signals, taken at 90 days. It can be observed that the time of flights for different series are different, producing a systematical phase difference in the time domain signals. This change in $t_{a}$ makes the propagation velocity decrease when the $\mathrm{SO}_{3}$ content in the original mix increases. Figure $6 \mathrm{~b}$ shows the average values of the ultrasonic wave velocity for each series at different testing times. The trend of the resulting curves is closely correlated with the evolution of the stiffness of the materials due to the setting and curing process of the concrete plus the addition of an extra amount of gypsum. Therefore, this measure is able to characterize each series both in terms of the rate of reaching a stable value, and the maximum ultrasonic wave velocity.

During the hydration of Portland cement, different hydrates are formed. C-S-H gel is the most important hydrate in terms of the strength development.

The gel particles formed connect to other gel particles, or to other hydrates, or to aggregate particles, reducing the porosity and increasing the solid network. This behaviour is confirmed through the ultrasonic attenuation measurements. Figure 7 a shows the time-domain signals for the $0 \%$ and $2 \%$ series at 90 days. In this plot, the differences in the amplitudes of the signals of both series can be observed, making more evident the contrast in the intensity of the wave at higher frequencies, where the $0 \%$ series has more cohesive elements in its structure than the $2 \%$ one.

The received signals were analysed in terms of their energy according to Eq. 5. Attenuation of the signals were calculated according to Eq. 6 . The total material attenuation values, $\alpha_{\text {mat }}$, observed for the different mortars are depicted in Figure 7b. The general trend of the attenuation values is a decay as the hydration process of the Portland cement matrix progresses. The reference series ( $0 \%$ can only be distinguished from the $1 \%$ and $1.5 \%$ series in the initial steps of the process. The decrease in attenuation for $0 \%$ series is due to the densification of the matrix and the increasing in the number of contact points and contact surface area. This attenuation decrease is produced in the first 28 days, from $5.5 \mathrm{~dB} / \mathrm{cm}$ to $4.1 \mathrm{~dB} / \mathrm{cm}$, suggesting that the ultrasonic wave transmission is achieved by means of the contact area among the gel and the different types of particles (other 


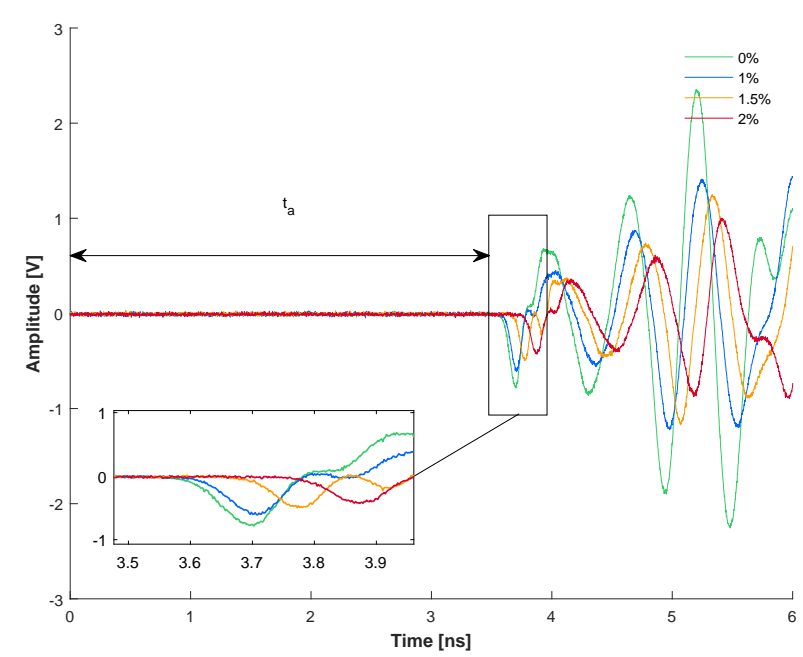

(a)

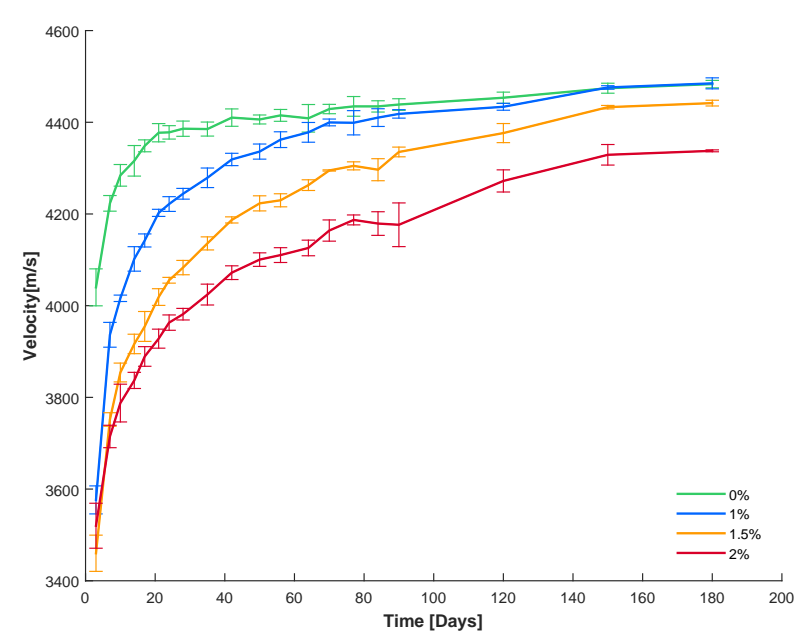

(b)

Figure 6: Results of ultrasonic pulse velocity test for all series. Figure 6a: the beginning of time-domain signals at 90 days and time of flight $\left(t_{a}\right)$ concept. Figure 6b: the results of the ultrasonic pulse velocity. Each data point represents the mean of three measurements.

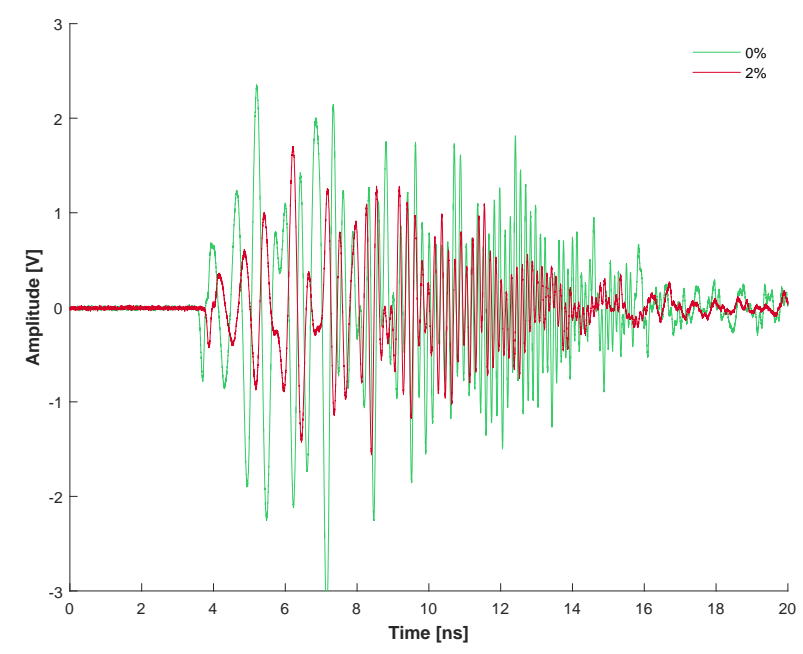

(a)

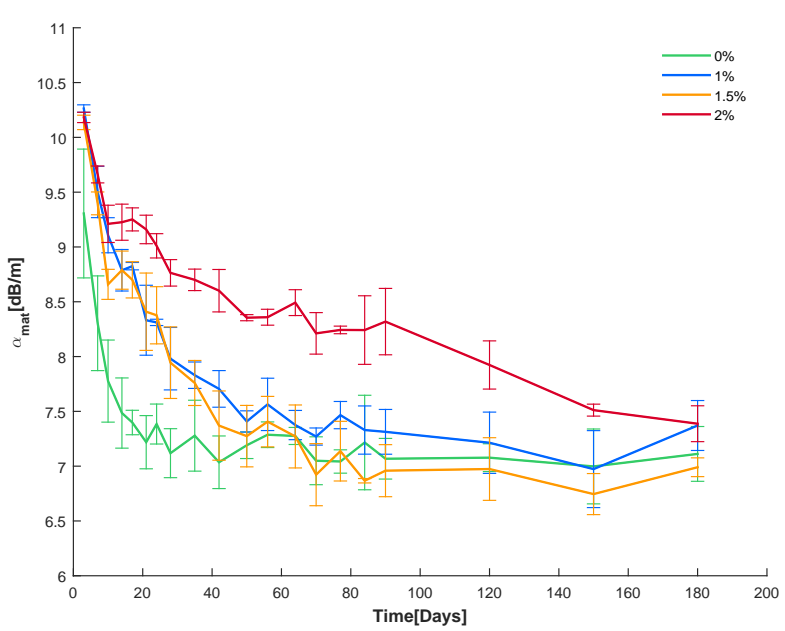

(b)

Figure 7: Results of ultrasonic attenuation test for all series. Figure 7a: the time-domain signals for the $0 \%$ and $2 \%$ series at 90 days. Figure 7b: the total material attenuation obtained by means of a linear chirp signal. Each data point represents the mean of three measurements.

hydrates, unhydrated particles, or sand particles). The effect in the $1 \%$ and $1.5 \%$ series of the addition of $\mathrm{SO}_{3}$ as gypsum produces a delay in the development of the solid network: the initial attenuation is 6 and $6.5 \mathrm{~dB} / \mathrm{cm}$, and after 28 days, this was reduced to $4.5 \mathrm{~dB} / \mathrm{cm}$, both reaching the same value. After this curing age, the evolution of the attenuation for both materials is similar to those found for $0 \%$ series. Nevertheless, the $2 \%$ series presents huge differences from the other series, remaining higher along the whole process. Thus, attenuation values after 28 days higher than $5 \mathrm{~dB} / \mathrm{cm}$ and $5.5 \mathrm{~dB} / \mathrm{cm}$ are reached after 60 days, oscillating until 80 days. After 90 days, the attenuation begins to decay until reaching values near those fro the $1 \%$ and $1.5 \%$ series at 180 days, when the expansion process seems to stop (at $0.08 \%$ expansion, Fig. 3a). 
The attenuation showed similar trends to the rest of the monitored parameters for all series, but it seems to be more sensitive to the mesoscale elements in the mortar structure rather their elastic constants, constituting an interesting way to evaluate damage processes in non-homogeneous materials like concrete.

\section{Conclusions}

In this paper, there were presented the results of monitoring an internal sulphate attack (ISA), which was exhaustive in terms of the number of measurements taken along the the experiment ( 180 days) as well as the number of methods used in order to characterize the process. Four types of mortar with different amounts of gypsum have been monitored by means of physical, microstructural and non-destructive tests. The experiment had been designed to reach low expansion rates ( $\leq 0.1 \%$ of expansion) in order to examine the sensitivity of the applied techniques.

The physical tests were to determine the expansion and mechanical strength parameters. The expansion analysis has shown the suitability of the fitting model proposed in the bibliography, increasing the slope of the expansion process $\left(\tau_{c h a r}\right)$ and maximum expansion rate $\left(\epsilon^{\infty}\right)$ as the $\mathrm{SO}_{3}$ content of the series rises. In the mechanical analysis, the series reached lower values of $\mathrm{R}_{c}$ and $\mathrm{R}_{f}$ as the gypsum content increases.

HRTG allowed qualitatively identifying the amount of expansive products formed during the whole process: the ettringite formed in the series rises as the initial amount of gypsum increases and the curing time advances. FESEM micrographs showed the needles of ettringite surrounding the C-S-H and portlandite phases for the high gypsum content series.

Impact acoustic resonance spectroscopy and ultrasonic measures have shown the accuracy of these non-destructive techniques applied to detect and characterize an ISA process. The dynamic modulus and ultrasonic pulse velocity have closely predicted the stiffness of the specimens, according to the aforementioned trends. However, the total material attenuation presented different trends, showing clear differences between the $2 \% \mathrm{SO}_{3}$ series and the rest of the series, reaching similar values at the end of the experiment. The attenuation monitoring is an interesting procedure for the assessment of low-level expansion processes in mortars which have suffered an internal sulphate attack.

\section{Acknowledgements}

This work has been supported by the Spanish Administration under grants TEC2011-23403, BIA2014-55311-C21-P and BIA2014-55311-C2-2-P. 


\section{References}

[1] M. Katsioti, N. Patsikas, P. Pipilikaki, N. Katsiotis, K. Mikedi, M. Chaniotakis, Delayed ettringite formation (DEF) in mortars of white cement, Construction and Building Materials 25 (2) (2011) 900-905.

[2] J. Skalny, J. Marchand, Sulphate attack on concrete, Spon Press, 2002.

[3] H. Taylor, Cement Chemistry, Thomas Telford, 1997.

[4] M. Collepardi, A state-of-the-art review on delayed ettringite attack on concrete, Cement and Concrete Composites 25 (2003) $401-407$.

[5] I. Casanova, L. Agulló, A. Aguado, Aggregate expansivity due to sulfide oxidation - I. Reaction system and rate model, Cement and Concrete Research 26 (1996) 993-998.

[6] A. Pavoine, X. Brunetaud, L. Divet, The impact of cement parameters on Delayed Ettringite Formation, Cement and Concrete Composites 34 (4) (2012) $521-528$.

[7] A. Pavoine, L. Divet, S. Fenouillet, A concrete performance test for delayed ettringite formation: Part I optimisation, Cement and Concrete Research 36 (12) (2006) 2138 - 2143.

[8] Y. Zhou, M. Li, L. Sui, F. Xing, Effect of sulfate attack on the stress-strain relationship of FRP-confined concrete, Construction and Building Materials 110 (2016) 235 - 250.

[9] H. N. Atahan, K. M. Arslan, Improved durability of cement mortars exposed to external sulfate attack: The role of nano \& micro additives, Sustainable Cities and Society 22 (2016) $40-48$.

[10] J. Małolepszy, E. Grabowska, Sulphate Attack Resistance of Cement with Zeolite Additive, Procedia Engineering 108 (2015) 170 - 176, 7th Scientific-Technical Conference on Material Problems in Civil Engineering MATBUD'2015.

[11] W. Piasta, J. Marczewska, M. Jaworska, Durability of Air Entrained Cement Mortars Under Combined Sulphate and Freeze-thaw Attack, Procedia Engineering 108 (2015) 55 - 62, 7th Scientific-Technical Conference on Material Problems in Civil Engineering MATBUD'2015.

[12] J. Stroh, B. Meng, F. Emmerling, Monitoring of sulphate attack on hardened cement paste studied by synchrotron (XRD), Solid State Sciences 48 (2015) $278-285$

[13] J. Yuan, Y. Liu, Z. Tan, B. Zhang, Investigating the failure process of concrete under the coupled actions between sulfate attack and drying-wetting cycles by using X-ray (CT), Construction and Building Materials 108 (2016) 129 - 138.

[14] V. Malhotra, N. Carino, Handbook on Nondestructive Testing of Concrete, Civil engineering, CRC Press, 2004.

[15] Y. Zhou, J. Gao, Z. Sun, W. Qu, A fundamental study on compressive strength, static and dynamic elastic moduli of young concrete, Construction and Building Materials 98 (2015) 137 - 145.

[16] V. Genovés, L. Soriano, M. Borrachero, J. Eiras, J. Payá, Preliminary study on short-term sulphate attack evaluation by non-linear impact resonance acoustic spectroscopy technique, Construction and Building Materials 78 (2015) 295 - 302.

[17] T. P. Philippidis, D. G. Aggelis, Experimental study of wave dispersion and attenuation in concrete., Ultrasonics 43 (7) (2005) 584-95, ISSN 0041-624X.

[18] S. Popovics, J. L. Rose, J. S. Popovics, The behaviour of ultrasonic pulses in concrete, Cement and Concrete Research 20 (2) (1990) 259 $-270$.

[19] L. Vergara, J. Gosálbez, J. Fuente, R. Miralles, I. Bosch, Measurement of cement porosity by centroid frequency profiles of ultrasonic grain noise, Signal Processing 84 (12) (2004) 2315-2324.

[20] L. Vergara, R. Miralles, J. Gosálbez, F. Juanes, L. Ullate, J. Anaya, M. Hernández, M. Izquierdo, NDE ultrasonic methods to characterise the porosity of mortar, NDT \& E International 34 (8) (2001) 557-562.

[21] D. Aggelis, T. Philippidis, Ultrasonic wave dispersion and attenuation in fresh mortar, NDT \& E International 37 (8) (2004) 617-631.

[22] ASTM, Standard Test Method for Length Change of Hydraulic-Cement Mortars Exposed to a Sulfate Solution, ASTM C 1012-04, 2004.

[23] M. V. Borrachero, J. Payá, M. Bonilla, J. Monzó, The use of thermogravimetric analysis technique for the characterization of construction materials, Journal of Thermal Analysis and Calorimetry (2008) 503-509.

[24] ASTM, Standard Test Method for Fundamental Transverse, Longitudinal, and Torsional Resonant Frequencies of Concrete Specimens, ASTM C 215-14, American Society for Testing Materials, 2014.

[25] J. Krautkrämer, H. Krautkrämer, Ultrasonic testing of materials, Springer-Verlag, ISBN 9783540117339, 1983.

[26] P. A. Gaydecki, F. M. Burdekin, W. Damaj, D. G. John, The propagation and attenuation of medium-frequency ultrasonic waves in concrete: a signal analytical approach, Measurement Science and Technology 3 (1) (1992) 126.

[27] M. Molero, I. Segura, S. Aparicio, M. G. Hernández, M. a. G. Izquierdo, On the measurement of frequency-dependent ultrasonic attenuation in strongly heterogeneous materials., Ultrasonics 50 (8) (2010) 824-8.

[28] C. Larive, Apports combinés de l'expérimentation et de la modélisation à la compréhension de l'alcali-réaction et de ses effets mécaniques, Etudes etrecherches des LPC., 1998.

[29] M. Zhang, M. Jiang, J. Chen, Variation of flexural strength of cement mortar attacked by sulfate ions, Engineering Fracture Mechanics 75 (17) (2008) 4948 - 4957, ISSN 0013-7944, fundamentals of Fracture.

[30] ACI-Committee-209, Prediction of Creep, Shrinkage, and Temperature Effects in Concrete Structures, American Concrete Institute Especial publication 76 (1982) 193-300.

[31] M. V. Borrachero, J. Payá, J. Monzó, The use of MaxRes for the investigation of partially hydrated Portland cement systems, Usercom (2000) 6-15. 